\title{
A Vaporization Rate Model for Flammable Liquid Pool under Vertical Air Jet Impingement
}

\author{
HONG-ZENG YU ${ }^{1}$, SAN-PING HO ${ }^{2}$ and ROBERT G. ZALOSH ${ }^{3}$ \\ ${ }^{1}$ FM Global \\ 1151 Boston-Providence Turnpike \\ Norwood, MA 02062, USA \\ ${ }^{2}$ Chang Jung Christian University \\ 396 Chang Jung Road \\ Sec. 1 Kway Jen, Tainan, Taiwan \\ ${ }^{3}$ Worcester Polytechnic Institute \\ 100 Institute Road \\ Worcester, MA 01609, USA
}

\begin{abstract}
A theoretical model was developed to predict the flammable liquid vaporization rate from a heated pool subjected to impingement of a vertical air jet. The model divides the air flow field into two regions: one is the bulk air jet turning region and the other is the thin boundary layer formed on the liquid surface. The model is based on the premise that the thickness of the boundary layer in which vapor diffusion takes place above a liquid pool is mainly controlled by the impinging air jet. The model predicts that the liquid vaporization rate increases with the pool temperature and increases linearly with the impinging velocity, as opposed to the square-root dependence in the case of air flow parallel to the pool surface. The model was validated with vaporization rate data of high flash-point liquids. It is shown in this paper that the vapor blowing effect on boundary layer thickness greatly diminishes as the impinging air velocity increases from quiescence to $3.3 \mathrm{~m} / \mathrm{s}$ for the high flash-point liquid pools analyzed in this study. The analysis also indicated that the boundary layer thickness on a small curbed pool could be greater than that predicted for an infinite pool. The resulting thicker fuel vapor diffusion layer tends to lead to lower vaporization rates than those expected from an infinite liquid pool under the same air impingement condition.
\end{abstract}

KEYWORDS: vaporization rate, flammable liquid pool, air jet impingement

\section{NOMENCLATURE}

$\begin{array}{llll}D & \text { Mass diffusivity }\left(\mathrm{m}^{2} / \mathrm{s}\right) & \delta & \text { Boundary layer thickness }(\mathrm{m}) \\ D_{\text {pool }} & \text { Liquid pool diameter }(\mathrm{m}) & \mu & \text { Dynamic viscosity }(\mathrm{kg} / \mathrm{ms}) \\ g & \text { Gravitational acceleration }\left(\mathrm{m} / \mathrm{s}^{2}\right) & v & \text { Kinematic viscosity }\left(\mathrm{m}^{2} / \mathrm{s}\right) \\ \dot{\mathrm{m}}_{\mathrm{evp}} & \text { Vaporization rate }(\mathrm{kg} / \mathrm{s}) & \rho & \text { Density }\left(\mathrm{kg} / \mathrm{m}^{3}\right) \\ p & \text { Pressure }\left(\mathrm{N} / \mathrm{m}^{2}\right) & \text { Subscripts } \\ r & \text { r coordinate }(\mathrm{m}) & c & \text { Centerline } \\ z & \text { z coordinate }(\mathrm{m}) & o & \text { Pool surface } \\ u & \text { Velocity in the } \mathrm{r} \text { direction }(\mathrm{m} / \mathrm{s}) & \mathrm{Z} & \text { An elevation above the pool } \\ v & \text { Velocity in the z direction }(\mathrm{m} / \mathrm{s}) & \delta & \text { The edge of boundary layer } \\ \text { Greek } & & & \\ \beta & \text { Constant }(1 / \mathrm{s}) & & \end{array}$




\section{INTRODUCTION}

Heated oil pool fires such as those originating from metal treatment and food processing operations are highly challenging to water spray and water mist spray systems [1,2]. When a water mist spray overpowers the fire plume of a curbed flammable liquid pool, it is typical that the flames in the pool's central region are pushed toward the pool edge $[3,4]$. When the central region of the liquid pool is free of flames under such conditions, fuel vapor is still being generated profusely on the non-flaming pool surface due to high oil temperature. For a water mist system designed for fire extinguishment, it is essential that the persisting flames along the pool edge do not flashback to the pool's central area and are gradually weakened and eventually extinguished before the system depletes its water supply.

Water mist sprays tend to induce stronger air currents than water sprays which produce larger droplets for the same water discharge rate [5,6]. For dual-fluid mist nozzles, air or other inert gases are discharged from the nozzle to promote water atomization, resulting in even higher air velocity in the water mist spray than the single-fluid nozzles. The air current in the water mist spray helps cooling the pool and diluting fuel vapor but at the same time also enhances the fuel vaporization rate. The fuel vaporization enhancement works against the first two aforementioned beneficial air current actions for reducing fuel vapor concentration above the pool surface. To ensure that the fuel vapor concentration in the pool's central region stays below the flammability limit during the extinguishing process, the fuel vapor generation rate as a function of pool surface temperature under air flow environment is therefore one of the key considerations in the process of water mist spray selection.

Correlations for evaporation rate from a liquid surface in environment of air flow parallel to the pool surface have been available [7]. However, such correlations are currently unavailable in the literature for a flammable liquid surface subjected to air jet impingement. Although the cooling of solid surfaces by impinging air jets has been investigated extensively, such as the studies listed in References 8-11, uncertainty arises when these heat transfer results are used to estimate liquid vaporization rates because both heat and mass transfer are involved in the process. On the other hand, studies were performed to investigate the burning behavior of solid combustibles in stagnation flow fields [12-15]. Again, the uncertainty is high in deducing liquid vaporization rates in combustion-free stagnation flow fields from these burning rate results.

This paper presents a theoretical model by which an explicit expression can be obtained for the vaporization rate from the stagnation area of a heated flammable liquid pool exposed to vertical impinging air current.

\section{THEORETICAL MODEL}

It has been shown that the heat transfer rate peaks at the stagnation point on a solid flat surface when impinged by an air jet with the jet axis perpendicular to the surface $[9,16]$. So it is expected that the vaporization rate on a liquid surface under a vertical impinging air jet would also reach a maximum at the stagnation point. From the fire protection point of view, the use of liquid vaporization rate determined in the stagnation area provides a conservative assessment on whether the fuel vapor mixture on the pool surface could be ignited. 
As illustrated in Fig. 1, the flow field in the stagnation area may be divided into two distinct regions: one is the bulk air jet turning region and the other is the thin boundary layer that forms on the liquid surface. The vaporization rate from the liquid surface is governed by the liquid's attempt to maintain the equilibrium vapor pressure at the liquid surface in a given air flow environment. The released fuel vapor then diffuses across the thin boundary layer and is swept away by the turning air jet. So the fuel vapor pressure (or concentration) tends to vary from its equilibrium value at the liquid surface to an ambient value (zero is assumed in the modeling below) at the edge of the boundary layer.

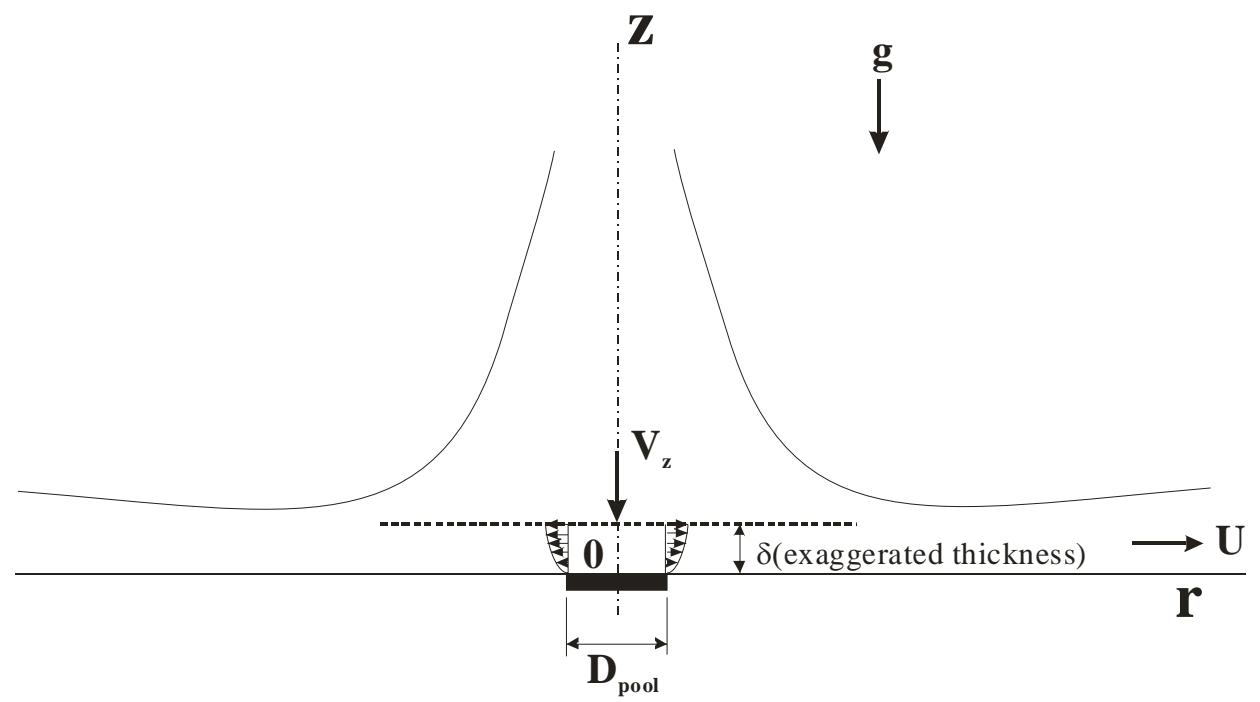

Fig. 1. An illustration of the physical model.

For typical fully developed water mist sprays used in fire protection, the velocity of the induced air current is around $3 \mathrm{~m} / \mathrm{s}$ or higher, which is at least two orders of magnitude greater than the blowing velocity of the fuel vapor released from the pool surface under free-burn conditions for typical hydrocarbon liquids [17]. Therefore, it is reasonable to assume that the diffusion depth of the fuel vapor is mainly controlled by the air jet impingement.

To determine the boundary layer thickness, the main concern is that the liquid surface tends to be indented by the impinging air jet, thus deviating from the flat surface condition. For an air jet with a centerline velocity of $5 \mathrm{~m} / \mathrm{s}$, the deepest liquid surface indentation is estimated to be about $3 \mathrm{~mm}$. Therefore, for typical air current induced by water mist sprays, the liquid surface in the stagnation area can be reasonably approximated as a flat surface due to the small surface curvature, assuming that the mist flow conforms to the air current perfectly so that no sputtering occurs on the liquid surface.

Another important consideration in the modeling is the effect of the turbulence in the air jet outside the boundary layer on the evaporation rate. For the case of normally impinging laminar air jet on a flat solid surface, the Nusselt number is proportional to the square root of the Reynolds number if the boundary layer is laminar, but is proportional to 0.8 power of the Reynolds number if the boundary layer is turbulent [18]. For impinging turbulent jets, studies have shown that the Nusselt number is proportional to the square root of Reynolds number, but with values higher than those expected for the case where 
the boundary layer is laminar $[5,9,10]$. The reasoning [9] is that, due to the strongly favorable radial pressure gradient in the stagnation area, the boundary layer behaves as a laminar layer but is disturbed by the turbulence carried in from the free jet. It has been reported that $15 \%$ free stream turbulence intensity could enhance heat transfer by $25 \%$ from the non-disturbed laminar layer [5]. For the case of vaporization on a heated pool, it is expected that the boundary layer in the stagnation area also behaves like a laminar layer and the free stream turbulence would induce similar vaporization enhancement.

Based on the above discussions, the following three primary assumptions are made for modeling the vaporization rate of a liquid pool subjected to impingement of a vertical air jet: 1) the liquid surface is flat; 2) the air jet is axisymmetrical, pointed vertically downward, and centered with the pool; and 3) the boundary layer is laminar.

From Schlichting [19], the thickness of the boundary layer in the stagnation area on an infinite flat surface induced by a normally impinging jet is

$$
\delta=2.0\left(\frac{v}{\beta}\right)^{1 / 2}
$$

In Eq. (1), $v$ is the gas kinematic viscosity in the boundary layer; $\beta$ is a constant which relates the horizontal and vertical components of air velocity to the radial distance from the stagnation point and vertical distance from the flat surface, i.e.,

$$
\mathrm{u}=\beta \mathrm{r} \quad \text { and } \quad \mathrm{v}=-2 \beta \mathrm{z}
$$

The next step is to relate the approaching air jet velocity to the thickness $\delta$.

Again, from Schlichting [19], the vertical component of the velocity at the edge of the boundary layer is

$\mathrm{v}_{\delta}=-2.8(v \beta)^{1 / 2}$

Using Eqs. 1 and 3, we have

$\mathrm{v}_{\delta}=-1.4(\delta \beta)$

Equations 1 and 4 lead to the following expression of the boundary layer thickness in the stagnation area on an infinite flat surface:

$\delta=-5.6\left(\frac{v}{\mathrm{v}_{\delta}}\right)$

which can be used to estimate the boundary layer thickness on a pool with no freeboard under a vertical air jet impingement. 
From the momentum equation in the radial direction (u-component) and Eq. 2, we can relate the constant $\beta$ and the radial pressure gradient near the stagnation point with the expression below,

$\beta=\left(-\frac{1}{\rho r} \frac{\partial \mathrm{p}}{\partial \mathrm{r}}\right)^{1 / 2}$

Donaldson et al. showed that the radial pressure gradient on a flat surface is greater than that on the surface inside a cylindrical cup, similar to a pool with freeboard, in the impingement region [20]. As a result, the $\beta$ value in Eq. 6 is expected to be smaller for a pool with freeboard than for an infinite pool or a pool without freeboard. From Eq. 4, the boundary layer on a liquid pool with freeboard is therefore expected to be thicker than that on an infinite pool for a constant impinging air velocity.

For a liquid pool with freeboard, the general expression for the boundary layer thickness is therefore expected to be

$\delta=-\mathrm{k}\left(\frac{v}{\mathrm{v}_{\delta}}\right)$

where $\mathrm{k}$ is a positive value and is a function of air jet characteristics on the pool surface, pool diameter and freeboard depth, provided that the blowing effect of evaporation at the pool surface on $\delta$ is negligible compared to the effect of the impinging air current.

Outside the boundary layer, the air temperature is the approaching air jet temperature and the fuel vapor concentration is assumed to be zero. So the problem is now reduced to film diffusion from the pool surface to the upper edge of the boundary layer. If the liquid vapor pressure at the pool surface is at equilibrium, the classical film diffusion solution gives the pool vaporization rate as follows [21]:

$\dot{\mathrm{m}}_{\mathrm{evp}}=\left(\frac{\pi}{4} \mathrm{D}_{\text {pool }}{ }^{2}\right)\left(\frac{\rho \mathrm{D}}{\delta}\right) \ln \left[1+\frac{\mathrm{Y}_{\mathrm{o}}-\mathrm{Y}_{\infty}}{1-\mathrm{Y}_{\mathrm{o}}}\right]$

where $\rho$ and $\mathrm{D}$ are the density and mass diffusivity of the gas mixture in the diffusion layer, and $Y_{o}$ and $Y_{\infty}$ are the saturated fuel vapor mass fraction at the pool surface and the fuel vapor mass fraction in the ambient, respectively.

Using Eq. 7, the liquid vaporization rate from a liquid pool is related to the air jet velocity as follows:

$\dot{\mathrm{m}}_{\mathrm{evp}}=\left(-\frac{\pi}{4 \mathrm{k}} \mathrm{D}_{\text {pool }} 2\right)\left(\frac{\rho \mathrm{Dv} \delta}{v}\right) \ln \left[1+\frac{\mathrm{Y}_{\mathrm{o}}-\mathrm{Y}_{\infty}}{1-\mathrm{Y}_{\mathrm{o}}}\right]$

Under the condition that

$\left(\mathrm{Y}_{\mathrm{O}}-\mathrm{Y}_{\infty}\right) /\left(1-\mathrm{Y}_{\mathrm{O}}\right)<<1$ 
Equation 9 can be approximated with

$\dot{\mathrm{m}}_{\mathrm{evp}}=\left(-\frac{\pi}{4 \mathrm{k}} \mathrm{D}_{\text {pool }}{ }^{2}\right)\left(\frac{\rho \mathrm{D}}{v}\right)\left(\frac{\mathrm{Y}_{\mathrm{o}}-\mathrm{Y}_{\infty}}{1-\mathrm{Y}_{\mathrm{o}}}\right) \mathrm{v}_{\delta}$

Equation 10 indicates that the fuel vaporization rate from a liquid pool is proportional to the impinging air velocity, as opposed to the case of air flow parallel to a semi-infinite surface where the vaporization rate is proportional to the square root of free stream air velocity [21].

Since the calculated values of $\delta$ is less than $1.3 \mathrm{~mm}$ for the experiments discussed below, it is reasonable to approximate $\mathrm{v}_{\delta}$ in Eq. 10 with the jet velocity at the elevation of pool surface when the pool is not present.

\section{EXPERIMENTAL VALIDATION AND DISCUSSIONS}

Few experimental data can be found in the literature for the fuel vaporization rate from a heated pool impinged normally by an air jet. In the following, fuel vaporization rates calculated from Eq. 10 will be compared with the data found in the literature for high flash-point liquids.

Limited data are available from Ho's thesis work on water spray suppression and intensification of high flash-point pool fires [22]. In studying the effect of fuel splattering by water sprays on fire intensification, Ho quantified in separate experiments the fuel vapor originating from the splashed fuel droplets and the fuel vapor from a heated pool subjected to an impinging air jet. He observed that the former fuel vapor source dominated the latter for the two high flash-point liquids used in his experiments. Ho's measurements of fuel vaporization rates from a heated pool are briefly described below.

A soybean oil of unknown composition and a mineral seal oil (CAS number 64742-46-7) were used in Ho's evaporation experiments. Both oils are in the Class IIIB category according to the NFPA 30 standard [23]. The flash points of the mineral seal oil and soybean oil are reported to be $137^{\circ} \mathrm{C}$ and $291^{\circ} \mathrm{C}$, respectively [22].

The oil vaporization rates were measured at selected oil temperature and impinging air velocities. In the experiments, a $0.3-\mathrm{m}$ diameter steel pan $76 \mathrm{~mm}$ high was positioned on a hot plate (Sybron Thermodyne Type 2200) which in turn was placed on an electronic scale (GSE series 4440). In these experiments, the pan was filled with the tested oil to result in a freeboard of about $13 \mathrm{~mm}$ deep. The oil was then heated to a designated temperature. In the heating process, a stirrer was used to obtain uniform oil temperature inside the pan. A temperature controller (Omega CN7000) was used to maintain the liquid pool at the designated temperature during the experiment. After the pool temperature reached the designated temperature, an air jet was discharged vertically from a nozzle (Spraying System 1/8 HH 1.5) located $0.91 \mathrm{~m}$ directly above the pool. The spray angle of the air jet was about 60 degrees. As a result, the jet diameter at the top of the pan was slightly greater than the pan diameter. An anemometer (Taylor Biram Model 3132) was used to measure the air velocity at an elevation of $0.15 \mathrm{~m}$ above the pan.

Figures 2 and 3 show the vaporization rate data of mineral seal oil and soybean oil obtained from Ref. 22. For mineral seal oil, at oil temperatures of $90^{\circ} \mathrm{C}$ and $110^{\circ} \mathrm{C}$, the experiments were conducted with no air jet impingement and with centerline air jet 


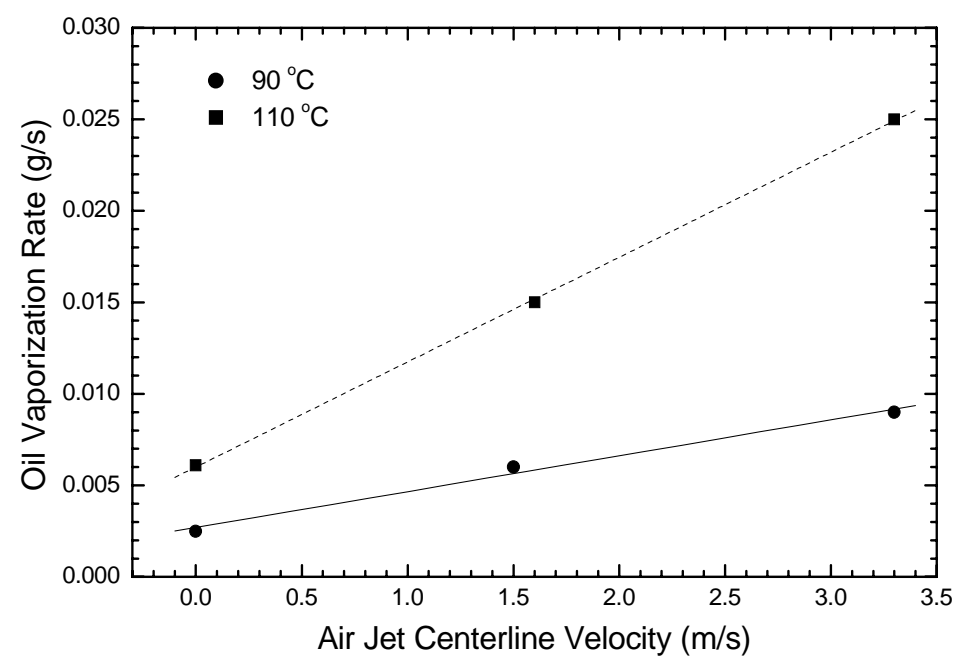

Fig. 2. Mineral oil vaporization rates from a $0.3-\mathrm{m}$ diameter pool impinged by an air jet originated $0.91 \mathrm{~m}$ above the pool surface. The oil temperature was at 90 or $110^{\circ} \mathrm{C}$.

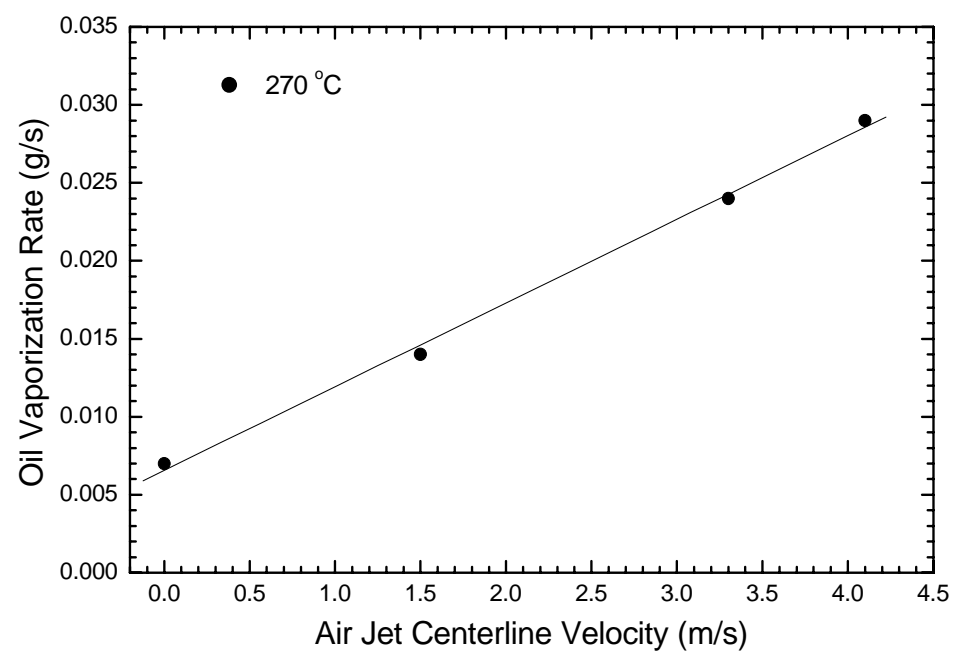

Fig. 3. Soybean oil vaporization rates from a $0.3-\mathrm{m}, 270^{\circ} \mathrm{C}$ pool impinged by an air jet originated $0.91 \mathrm{~m}$ above the pool surface. 
velocities of $1.5 \mathrm{~m} / \mathrm{s}$ and $3.3 \mathrm{~m} / \mathrm{s}$. For soybean oil, the experiments were conducted with an oil temperature of $270^{\circ} \mathrm{C}$ and with the same air impingement conditions for the mineral oil except that an additional air jet centerline velocity of $4.1 \mathrm{~m} / \mathrm{s}$ was employed. Both Figs. 2 and 3 show that, at a given oil temperature, the oil vaporization rate increases linearly with the impinging air velocity, as indicated by Eq. 10. By performing least square regression of the data, the vaporization rate of the mineral seal oil can be expressed by:

$\dot{\mathrm{m}}_{\mathrm{evp}}=0.00270+0.00196 \mathrm{u}_{\mathrm{C}}$ for $90^{\circ} \mathrm{C}$ and $\mathrm{u}_{\mathrm{C}} \leq 3.3 \mathrm{~m} / \mathrm{s}$

and

$\dot{\mathrm{m}}_{\mathrm{evp}}=0.00601+0.00573 \mathrm{u}_{\mathrm{C}}$ for $110^{\circ} \mathrm{C}$ and $\mathrm{u}_{\mathrm{C}} \leq 3.3 \mathrm{~m} / \mathrm{s}$

The vaporization rate of soybean oil is

$\dot{\mathrm{m}}_{\mathrm{evp}}=0.00656+0.00537 \mathrm{u}_{\mathrm{C}}$ for $270{ }^{\circ} \mathrm{C}$ and $\mathrm{u}_{\mathrm{C}} \leq 4.1 \mathrm{~m} / \mathrm{s}$

The unit of the vaporization rate in the above three equations is in $\mathrm{g} / \mathrm{s}$.

Since the value of $\mathrm{k}$ in Eq. 7 is unknown for each aforementioned impinging air velocity used in the experiments described in Ref. 22, Eq. 10 cannot be used directly to make predictions. However, by assuming that the oil vapor diffusion depth $\delta$ was little affected by the pool temperature under the air impingement conditions described above, the vaporization rates at a given oil temperature can then be predicted using Eq. 10 after the diffusion depth at the same air impinging velocity is determined for a different pool temperature. The above assumption is reasonable since the oil vapor blowing velocity in Ho's experiments is much lower than the air jet velocity. As a result, the diffusion depth is expected to be mainly controlled by the air jet impingement. When the air jet is absent, the diffusion depth is expected to be affected by the pool temperature, freeboard depth and room draft.

To calculate the vaporization rate using Eq. 10, the density, mass diffusivity and kinematic viscosity of the gas mixture in the diffusion layer has to be first estimated, as well as the oil vapor mass fraction at the pool surface. Since most of the properties of soybean oil required in the analysis are not available (particularly the vapor pressure information), the discussion below is focused on the mineral seal oil.

The Material Safety Data Sheet (MSDS) does not provide the molecular formula of the mineral seal oil [24]. However, the MSDS does state that it is a hydro-treated middle distillate with boiling point ranging from 277 to $321^{\circ} \mathrm{C}$ and flash point ranging from 120 to $135^{\circ} \mathrm{C}$. The material property data base of Reference 25 shows that, in the group of paraffin compounds, hexadecane $\left(\mathrm{C}_{16} \mathrm{H}_{34}\right)$ gives the best match to both the flash point and boiling point of the mineral seal oil. The flash point and boiling point of the hexadecane are reported to be $135^{\circ} \mathrm{C}$ and $289^{\circ} \mathrm{C}$, respectively [25]. As a result, it is assumed that the vapor pressure of hexadecane can reasonably represent that of the mineral seal oil. The oil vapor pressures of hexadecane at $90^{\circ} \mathrm{C}$ and $110^{\circ} \mathrm{C}$ are 63 and 178 Pascal [25], respectively. The Schmidt number (ratio of kinematic viscosity and mass diffusivity) of dilute hexadecane-air mixture is estimated to be about 2.8 [18]. Since the low 
concentration of oil vapor, the density and kinematic viscosity of the vapor-air mixture in the diffusion layer can be reasonably approximated by those of air at the temperature equal to the average of the pool surface temperature and the ambient temperature (around $20^{\circ} \mathrm{C}$ ). Therefore, in the following analysis, the air density and kinematic viscosity of $1.071 \mathrm{~kg} / \mathrm{m}^{3}$ and $1.868 \times 10^{-5} \mathrm{~m}^{2} / \mathrm{s}$ (at $55^{\circ} \mathrm{C}$ ) will be used for the $90^{\circ} \mathrm{C}$ pool, and $1.039 \mathrm{~kg} / \mathrm{m}^{3}$ and $1.978 \times 10^{-5} \mathrm{~m}^{2} / \mathrm{s}$ (at $65^{\circ} \mathrm{C}$ ) will be used for the $110^{\circ} \mathrm{C}$ pool. The mass diffusivity of the vapor-air mixture is then approximated by the ratio of air kinematic viscosity and Schmidt number.

Based on the above values of the air-vapor mixture properties and the vaporization rates measured with the $90^{\circ} \mathrm{C}$ pool, the diffusion depths and the corresponding $\mathrm{k}$ values were calculated using Eq. 8 and Eq. 7, respectively, which are presented in Table 1. As expected, the diffusion depth decreases as the air jet velocity on the pool surface increases. The calculated diffusion depths are greater than those predicted for an infinite flat surface, i.e., $0.055 \mathrm{~mm}$ for an impinging air velocity of $1.5 \mathrm{~m} / \mathrm{s}$ and $0.025 \mathrm{~mm}$ for $3.3 \mathrm{~m} / \mathrm{s}$. The diffusion depth under no impingement case is $1.02 \mathrm{~mm}$, much smaller than the freeboard depth of $13 \mathrm{~mm}$. It is speculated that the reason why the vapor layer does not reach the pan rim for no air jet impingement is due to the small vaporization rate, room draft and relatively large ratio of pan diameter versus freeboard.

Table 1. Calculated oil vapor diffusion depths and $\mathrm{k}$ values based on the vaporization data obtained with a $90^{\circ} \mathrm{C}$ pool.

\begin{tabular}{|c|c|c|c|}
\hline $\begin{array}{c}\text { Centerline Air } \\
\text { Jet Velocity } \\
(\mathbf{m} / \mathbf{s})\end{array}$ & $\begin{array}{c}\text { Measured } \\
\text { Vaporization Rate }\end{array}$ & $\begin{array}{c}\text { Calculated } \\
\text { Diffusion Depth } \\
\text { Using Eq. (8) } \\
\mathbf{( m m )}\end{array}$ & $\begin{array}{c}\text { k Value in } \\
\text { Eq. (7) }\end{array}$ \\
\hline 0 & $\mathbf{( g / s )}$ & 1.02 & - \\
\hline 1.5 & 0.0025 & 0.42 & 34 \\
\hline 3.3 & 0.006 & 0.29 & 50 \\
\hline
\end{tabular}

After the $\mathrm{k}$ values are determined, the vaporization rates for the $110^{\circ} \mathrm{C}$ pool can be predicted with Eq. 10. As shown in Table 2, the predicted vaporization rates at air velocities of 1.5 and $3.3 \mathrm{~m} / \mathrm{s}$ agree well with the corresponding measured rates. The predicted rate for no air impingement was obtained with Eq. (8) and the diffusion depth of $1.02 \mathrm{~mm}$ determined for the $90^{\circ} \mathrm{C}$ pool, which also has a good agreement with the measured value, but with a slightly higher rate. Under the absence of air jet, the diffusion depth tends to be thicker as pool temperature increases. Therefore, it is expected that using the thinner diffusion depth determined for the $90^{\circ} \mathrm{C}$ pool overestimates the vaporization rate for the $110^{\circ} \mathrm{C}$ pool. The calculated diffusion depth of $1.21 \mathrm{~mm}$ (using the measured vaporization rate and Eq. 8) confirms the above expectation. The calculated diffusion depths for $\mathrm{u}=1.5$ and $3.3 \mathrm{~m} / \mathrm{s}$ also agree well with the corresponding depths for the $90^{\circ} \mathrm{C}$ pool as shown in Table 1 . The variations of diffusion depth with impinging air velocity exhibited in both Tables 1 and 2 indicate that the effect of vapor blowing from the pool surface on the diffusion depth diminishes quickly as the impinging velocity increases for the data analyzed in this study. 
Table 2. Predicted oil vaporization rates for the $110^{\circ} \mathrm{C}$ pool based on the diffusion depths and $\mathrm{k}$ values presented in Table 1.

\begin{tabular}{|c|c|c|c|}
\hline $\begin{array}{c}\text { Centerline Air } \\
\text { Jet Velocity }\end{array}$ & $\begin{array}{c}\text { Measured } \\
\text { Vaporization Rate }\end{array}$ & $\begin{array}{c}\text { Predicted } \\
\text { Vaporization Rate } \\
\text { Using Eq. (10) } \\
\mathbf{( m / s} / \mathbf{s})\end{array}$ & $\begin{array}{c}\text { Calculated } \\
\text { Diffusion Depth } \\
\text { Using Eq. (8) } \\
\mathbf{( m m )}\end{array}$ \\
\hline 0 & $\mathbf{( g / s )}$ & $0.0073^{\mathrm{a}}$ & $1.21^{\mathrm{b}}$ \\
\hline 1.5 & 0.0061 & 0.017 & $0.49^{\mathrm{b}}$ \\
\hline 3.3 & 0.015 & 0.025 & $0.30^{\mathrm{b}}$ \\
\hline
\end{tabular}

${ }^{\mathrm{a}}$ The rate for no air impingement was calculated with Eq. 8 and with the diffusion depth of $1.02 \mathrm{~mm}$ (presented in Table 1) determined for the $90^{\circ} \mathrm{C}$ pool.

${ }^{\mathrm{b}}$ Calculated with the measured vaporization rates for the $110^{\circ} \mathrm{C}$ pool.

\section{CONCLUSIONS}

A theoretical model was developed for the prediction of liquid vaporization rates from a heated flammable liquid pool impinged by a vertical air jet. The model is based on the assumption that the thickness of the boundary layer in which vapor diffusion takes place above the liquid pool is mainly controlled by the impinging air jet, and little affected by the blowing effect of the vaporization process. The model correctly predicts that the liquid vaporization rate increases with pool temperature and increases linearly with impinging air velocity. The model predictions agree well with the vaporization rate data obtained for high flash-point liquids. The analysis of available high flash-point vaporization data showed that the blowing effect on the boundary layer thickness diminishes quickly as the impinging velocity increases. The analysis also showed that the boundary layer thickness on a curbed pool tends to be thicker than that predicted for an infinite pool. The thicker layer leads to lower vaporization rates as compared to those expected from an infinite pool at the same liquid temperature and under the same air impingement condition.

The vaporization rate model presented in this paper is useful in determining the reignition propensity in the flame-absent area of a burning pool under the impingement of water mist sprays. The model is also useful for the risk assessment of fuel vapor explosion originating from a flammable liquid pool or spill in an environment of forced downward ventilation.

It is recommended that the model be further validated with other low volatility, single component liquids. The general applicability of the model should also be evaluated with vaporization rate measurements made with high volatility liquids, where stronger vapor blowing action from a heated pool is expected to have greater impact on the thickness of the boundary layer induced by an impinging air jet.

\section{REFERENCES}

[1] Liu, Z. and Kim, A.K., "Fire Protection of a Restaurant Cooking Area with Water Mist System," Proceedings of the Third International Conference on Fire Research and Engineering, Society of Fire Protection Engineers, 1999, pp. 268271. 
[2] Nam, S., "Application of Water Sprays to Industrial Oil Cooker Fire," Fire Safety Science -- Proceedings of the Seventh International Symposium, International Association for Fire Safety Science, 2003, pp. 469-480.

[3] Yu, H-Z, Ferron, R.P., Dobson, P.H., Barsamian, C., Hanna M. and Gameiro V., "An Extrapolation Methodology for Pool Fire Extinguishment by Local Application Water Mist Systems," Fire Safety Science -- Proceedings of the Seventh International Symposium, International Association for Fire Safety Science, 2003, pp. 519-530.

[4] Kokkala, M., "Fixed Water Sprays Against Open Liquid Pool Fire," Fire Suppression Research - Proceedings of the First International Conference, Stockholm, May 5-8, 1992, pp. 129-158.

[5] Rasbash, D.J., "The Extinction of Fires by Water Sprays," Fire Research Abstracts and Reviews, 4 -5:28-53 (1962-63).

[6] Grant, G., Brenton, J. and Drysdale, D., "Fire Suppression by Water Sprays," Progress in Energy and Combustion Science, 26: 79-130, 2002.

[7] Zalosh, R.G., Industrial Fire Protection Engineering, John Wiley \& Sons, West Sussex, England, 2003.

[8] Donaldson, C.D., Snedeker, R.S. and Margolis, D.P., “A Study of Free Jet Impingement. Part 2: Free Jet Turbulent Structure and Impingement Heat Transfer," Journal of Fluid Mechanics, 45, 3: 477-512, 1971.

[9] McCormick, D.C., Test, F.L. and Lessman, R.C., "The Effect of Free-Stream Turbulence on Heat Transfer from a Rectangular Prism," Journal of Heat Transfer, 106: 268-275, 1984.

[10] Striegl, S.A. and Diller, T.E., "An Analysis of the Effect of Entrainment Temperature on Jet Impingement Heat Transfer," Journal of Heat Transfer, 106: 804-810, 1984.

[11] Raj, S.A., "A Complete Analytical Solution to Laminar Heat Transfer in Axisymmetric Stagnation Point Flow," International Journal of Heat Mass Transfer, 30: 2441-2444, 1987.

[12] Kiyoshi, M., Koyama, A. and Uehara, K., "Fluid-Mechanics Effects on the Combustion Rate of Solid Carbon,” Combustion and Flame, 25: 57-66, 1975.

[13] Adomeit, G., Hocks, W. and Henriksen, K., "Combustion of a Carbon Surface in a Stagnation Point Flow Field,” Combustion and Flame, 59: 273-288, 1985.

[14] Makino, A., "A Theoretical and Experimental Study of Carbon Combustion in Stagnation Flow," Combustion and Flame, 81: 166-187, 1990.

[15] Burluka, A.A. and Borghi, R., "Stretch Effect on the Evaporation Rate in Fendell’s Problem,” Combustion and Flame 122: 227-232, 1975.

[16] Sozbir, N., Chang, Y.W. and Yao, S.C., "Heat Transfer of Impacting Water Mist on High Temperature Metal Surfaces,” Journal of Heat Transfer, 125: 70-74, 2003. 
[17] Tewarson, A., "Generation of Heat and Chemical Compounds in Fires," The SFPE Handbook of Fire Protection Engineering ( $3^{\text {rd }}$ ed), DiNenno P.J. (ed.), Nation Fire Protection Association, Quincy, MA 02269, 2002, Section 3, Chapter 4.

[18] Kays, W.M., Convective Heat and Mass Transfer, McGraw-Hill Book Company, New York, 1966.

[19] Schlichting, H., Boundary Layer Theory, McGraw-Hill Book Company, New York, 1968.

[20] Donaldson, C.D., Snedeker, R.S. and Margolis, D.P., “A Study of Free Jet Impingement. Part 1: Mean Properties of Free and Impinging Jets,” Journal of Fluid Mechanics, 45, 2: 281-319, 1971.

[21] Glassman, I., Combustion, Academic Press, New York, 1977.

[22] Ho, S-P, "Water Spray Suppression and Intensification of High Flash Point Hydrocarbon Pool Fires,” Worcester Polytechnic Institute, Ph.D. Thesis, Worcester, Massachusetts, USA, 2003.

[23] “NFPA 30: Flammable and Combustible Liquids Code," National Fire Protection Association, 2003 Edition, Quincy, Massachusetts, USA.

[24] “Mineral Seal Oil Material Safety Data Sheet,” MSDS No. 19540, Revision Date 12/04/2000, CITGO Petroleum Corporation, Rolling Meadows, Illinois, USA.

[25] “The Properties of Gases and Liquids,” Design Institute for Physical Properties, American Institute of Chemical Engineers, New York, New York, USA. 